\title{
Recurrent epistaxis: predicting risk of 30-day readmission, derivation and validation of RHINO-ooze score*
}

\author{
A. Addison, C. Paul, R. Kuo, A. Lamyman, P. Martinez-Devesa, R. Hettige \\ Otorhinolaryngology, John Radcliffe Hospital, Oxford, Headley Way, United Kingdom
}

Rhinology 55: 99-105, 2017

https://doi.org/10.4193/Rhino16.259

*Received for publication:
September 8, 2016
Accepted: January 24, 2017

\begin{abstract}
Background: To derive and validate a predictive scoring tool (RHINO-ooze score) with good sensitivity and specificity in identifying patients with epistaxis at high risk of 30 day readmission and to enable risk stratification for possible definitive intervention.

Methods: Using medical databases, we searched for "factors influencing recurrent epistaxis". The information ascertained together with our analysis of retrospective data on patients admitted with epistaxis between October 2013 and September 2014, was used as the derivation cohort to develop the predictive scoring model (RHINO-ooze score). The tool was validated by performing statistical analysis on the validation cohort of patients admitted with epistaxis between October 2014 and October 2015. Multiple linear regressions with backwards elimination was used to derive the predictive model. The area under the curve (AUC), sensitivity and specificity were calculated.
\end{abstract}

Results: 834 admissions were encountered within the study period. Using the derivative cohort $(n=302)$ the RHINO-ooze score with a maximum score of 8 from five variables (Recent admission, Haemorrhage point unidentified, Increasing age $>70$, posterior Nasal packing, Oral anticoagulant) was developed. The RHINO-ooze score had a chi-square value of 99.72 with a significance level of $<0.0001$ and hence an overall good model fit. Comparison between the derivative and validation groups revealed similar rates of 30-day readmission between the cohorts. The sensitivity and specificity of predicting 30-day readmission in high risk patients with recurrent epistaxis (RHINO-ooze score $\geq 6$ ) was $81 \%$ and $84 \%$, respectively.

Conclusions: The RHINO-ooze scoring tool demonstrates good specificity and sensitivity in predicting the risk of 30 day readmission in patients with epistaxis and can be used as an adjunct to clinical decision making with regards to timing of operative intervention in order to reduce readmission rates.

Key words: nose, epistaxis

\section{Introduction}

It is estimated that 1 in 2 of the general population will experience epistaxis at least once in their life time. $6 \%$ will present to an emergency department requiring some form of medical intervention ${ }^{(1)}$. Epistaxis contributes to a significant workload for otolaryngologists and can lead to significant morbidity and rarely mortality. The majority of patients with epistaxis are ma- naged conservatively with either silver nitrate cautery or intranasal pack insertion with a few requiring operative intervention or embolization (2).

Over $20 \%$ of patients admitted under otolaryngologists with epistaxis will have recurrent episodes of bleeding requiring readmission and hospital management ${ }^{(3)}$. This can significantly impact on morbidity, mortality, cost and length of hospital stay. 
Various factors have been alluded to as potential reasons for this high rate of readmission, it has been suggested that patient factors such as age, co-morbidities, use of oral anticoagulants, and presence of systemic diseases such as hypertension contribute significantly to recurrent admissions ${ }^{(4-6)}$. The impact of initial treatment modality, grade of doctor administering treatment and identification of bleeding point on admission has not been adequately studied; A few retrospective studies address this important issue. There is some level III evidence to suggest that these factors influence recurrence of epistaxis ${ }^{(7-9)}$.

A fifth of patients continue to have recurrent episodes, and a percentage of these patients will require further intervention before subsequent resolution is achieved ${ }^{(10,11)}$. The morbidity inflicted on these patients by the interventions used can be significant both in the acute treatment phase (airway obstruction and cardiac events) or may lead to sequelae such as septal perforation. Early recognition of patients, who are likely to require readmissions, will enable risk stratification for targeted definitive management.

\section{Materials and methods}

\section{Literature review}

In February 2016, we searched the Cochrane library (23 hits), EMBASE (34 hits), PubMed (231 hits) and CINAHL (2 hits) using "factors influencing recurrent epistaxis" as keywords. The "related article" aid was used to search for other articles. Finally the references of selected articles were cross referenced.

\section{Data collection - derivation cohorts}

We collated retrospective data on all patients admitted under the otolaryngology team at a tertiary centre over a one year period (October 2013 to September 2014). We collected data under the following headings: age, sex, co-morbidities, anticoagulant use, length of stay, aetiology, site of bleeding, haemoglobin level, international normalisation ratio (INR), platelet levels, transfusion requirement, number of readmissions, period between readmissions and type of treatment administered. We excluded patients below the age of 18 , those with coagulopathies and traumatic epistaxis. Primary model outcome of 30 day readmission rate was used, and variables which showed an association with this outcome on univariate analysis were included as potential covariates in a multiple logistic regression model with backwards elimination. Variable selection was based on statistical significance and variables with $P$ value $>0.1$ were eliminated. Discrimination of the model was assessed by the receiver operation characteristic curve. The overall risk predictive score was calculated by dividing the lowest beta-coefficient value of the multiple logistic regressions with the beta coefficient values of the other variables resulting in a predictive model with a minimum and a maximum score of zero and eight, respectively.

\section{Data collection - validation cohorts}

Retrospective data was collected on all patients admitted under the otolaryngology team at tertiary centre over a one year period (October 2014 to October 2015). We validated the 30-day readmission rate by using the RHINO-OOZE score generated from the derivation cohort. Data analysis was performed using STATA statistical software (Version 7.0; STATA Corp, College Station, TX, USA).

\section{Results}

Literature review

The readmission rate of patients who present with epistaxis has been quoted as being over $20 \%{ }^{(10)}$. Although there are no randomised control trials investigating the various patient groups and their risks of recurrence, coagulopathic patients (hereditary haemorrhagic telangiectasia, leukaemia, etc.) have been shown to have an increased risk of recurrence irrespective of the initial treatment offered ${ }^{(11)}$. Most readmissions occur either immediately after initial treatment or within the first few weeks, although recurrence of epistaxis can occur many years after initial episode (12).

Identification of the bleeding point is key to the management of epistaxis. Approximately $80-90 \%$ of epistaxis occurs along the anterior nasal septum at Kiesselbach's (Little's) area and $10 \%$ are said to be posterior epistaxis occurring via branches of the sphenopalatine artery ${ }^{(13)}$.

Although there is little level 1 evidence supporting the risk of an unidentified bleeding point on recurrence rate of epistaxis and re-admission, there is level $2 b$ (retrospective studies) evidence to support the notion that an unidentified bleeding point at initial presentation leads to increased recurrence and readmission rates ${ }^{(14,15)}$. Patients in whom a bleeding point is not immediately identifiable are usually managed by nasal packing and further management is provided after removal of the nasal packing. Some authors advocate the use of rigid endoscopes to identify bleeding point and provide chemical or electro-cautery in these patients ${ }^{(16,17)}$. This presents its own challenges, not least the difficulty to perform such procedures under local anaesthesia without appropriate training, in the presence of significant epistaxis and an anxious patient.

Epistaxis appears to have a bimodal age distribution, with most cases occurring before age 10 or between 45 and 65 . Hospital admission for epistaxis increases progressively with age, but the available data often do not control for aspirin or anticoagulant use. Ageing is associated with anatomical and physiological changes in the nasal tissue which leads to degeneration of the mucociliary apparatus, fragmentation and weakness of the septal cartilage leading to airflow turbulence. These factors together with atherosclerotic changes to the vascular system of the nasal cavity contribute to the increase incidence of epistaxis among the elderly population ${ }^{(18)}$. 
Table 1. Univariate logistic analysis of the variables of the derivative cohort.

\begin{tabular}{|c|c|c|c|c|}
\hline Variables & $\begin{array}{l}\text { No (\%) with } \\
\text { Variable }\end{array}$ & $\begin{array}{l}\text { Derivation Cohort } \\
\text { No (\%) with } \\
\text { Variable who were } \\
\text { readmitted }\end{array}$ & Odds ratio $(95 \% \mathrm{Cl})$ & p Value \\
\hline Age ( $\geq 70$ years) & $133(44.04)$ & $44(55.00)$ & $1.71(1.02-2.85)$ & 0.042 \\
\hline Gender (Male) & $172(56.95)$ & $43(53.75)$ & $0.84(0.50-1.400$ & 0.501 \\
\hline Length of stay during admission & $188(62.25)$ & $43(53.75)$ & $0.62(0.37-1.04)$ & 0.07 \\
\hline Oral anticoagulation & $104(34.37)$ & $53(66.25)$ & $4.94(3.06-9.16)$ & $<0.0001$ \\
\hline Nasal packing (posterior pack inserted during admission) & $78(25.83)$ & $43(53.75)$ & $5.23(3.52-10.97)$ & $<0.0001$ \\
\hline Haemorrhage point unidentified & $79(26.16)$ & $41(51.25)$ & $4.84(2.91-8.92)$ & 0.008 \\
\hline Drop in Haemoglobin on admission & $161(53.31)$ & $37(46.25)$ & $1.045(0.84-1.29)$ & 0.689 \\
\hline Time elapsed before pack removed & $250(82.78)$ & $69(82.14)$ & $0.958(0.729-1.259$ & 0.759 \\
\hline Recent admission (within the last 30 days) & $49(61.25)$ & $27(51.02)$ & $3.045(1.18-7.83)$ & 0.018 \\
\hline
\end{tabular}

Posterior epistaxis account for about $10 \%$ of patients with epistaxis, these category of patients are more likely to require surgical intervention either on initial or subsequent readmissions. Many patients with posterior epistaxis experience clinically significant complications; recurrent re-admission is said to be higher in this patient group and more so in patients managed by conservative means (nasal packing and attempted cautery) (19). Various retrospective and prospective comparative studies have investigated the use of techniques in the management of posterior epistaxis and have found reduced readmission rates and morbidity in cohorts with early interventions (artery ligation, cautery or embolization) compared with cohorts who had nasal packing ${ }^{(20-23)}$. The Wexham criterion was proposed by Lakhani et al. (24) to help identify patients who may require SPA ligation for intractable posterior epistaxis. The criteria included: 1) Persistent posterior epistaxis uncontrolled by packing; 2 ) Haemoglobin drop > 4g/dL and/or blood transfusion required; 3) Three episodes of recurrent epistaxis requiring re-packing during a single admission; 4) Repeated hospital admission for recurrent ipsilateral epistaxis ( $>3$ occasions in the last three months) ${ }^{(24)}$. Although controversial, it has also been, suggested that sphenopalatine artery ligation with concomitant anterior ethmoidal artery ligation may be more effective in managing posterior epistaxis than sphenopalatine artery ligation alone ${ }^{(25)}$.

Patients taking anticoagulants tend to have a higher tendency of epistaxis compared to the general population. There is level $2 \mathrm{~b}$ evidence supporting increasing prevalence, recurrence and complication amongst this patient cohort. Newer anticoagulants such as factor Xa inhibitors (eg. rivaroxaban) presents a challenge not only with reversibility but also with lack of evidence in the management of patients on these newer drugs who presents with epistaxis. Current research suggests that anticoagulants such as vitamin K antagonist (warfarin), acetylsalicylic acid (aspirin) and thienopyridine antiplatelet agent (clopidogrel) to be the main culprits in recurrent epistaxis. Stopping or reversing these anticoagulants during acute bleeds remain controversial and may require specialist input ${ }^{(26,27)}$.

\section{Other factors}

Male preponderance: among hospitalized patients, there is male predominance up to 50 years, after which the sex distribution equalizes. There are no reports of increase rates of recurrent epistaxis in either sex.

Hypertension: The association between hypertension and epistaxis is uncertain. Multiple studies have linked hypertension to nosebleeds, although studies specifically exploring this relationship have been unable to confirm the association ${ }^{(27,28)}$. Some data suggest that long-standing hypertension may contribute to an elevated risk of epistaxis, most likely due to its vasculopathic effects. Some specialists suggest that hypertension does not cause epistaxis but does prolong episodes and can lead to readmissions ${ }^{(29)}$. The authors practice is to treat hypertensive patients with pharmacotherapy prior to embarking on definitive interventions.

Initial management: There is little research comparing the commonly used techniques in managing epistaxis and the rate of recurrence/readmission following such interventions. One study from China compared the use of an endoscopic microwave technique, anterior packing of nasal cavity and trichloroacetic acid cautery in the management of anterior epistaxis and found the microwave technique superior in terms of reducing recurrence ${ }^{(30)}$. Two small randomized trials and observational data suggest; there is no difference between a nasal tampon and the 
Table 2. The 5 significant variables in a multivariate logistic regression analysis with associated $\beta$ coefficients.

\begin{tabular}{|lcccc}
\hline Variable & $\begin{array}{c}\boldsymbol{\beta} \text { Coef- } \\
\text { ficient }\end{array}$ & $\begin{array}{c}\text { Std. } \\
\text { Error }\end{array}$ & Wald & P \\
\hline $\begin{array}{l}\text { Recent admission with } \\
\text { epistaxis } \leq 30 \text { days }\end{array}$ & 0.98750 & 0.34502 & 8.1918 & 0.0042 \\
$\begin{array}{l}\text { Haemorrhage point } \\
\text { unidentified }\end{array}$ & 1.35911 & 0.34026 & 15.9541 & 0.0001 \\
\hline $\begin{array}{l}\text { Age } \geq 70 y e a r s \\
\text { Nasal posterior pack }\end{array}$ & 0.87157 & 0.33704 & 6.6872 & 0.0097 \\
\hline required & 1.77838 & 0.34507 & 26.5598 & $<0.0001$ \\
\hline $\begin{array}{l}\text { Oral anticoagulant } \\
\text { Constant }\end{array}$ & 1.36230 & 0.32332 & 17.7537 & $<0.0001$ \\
\hline
\end{tabular}

Rapid Rhino balloon catheter in controlling epistaxis ${ }^{(31)}$.

\section{Analysis - RHINO-ooze score derivation cohort}

397 patients were admitted between October 2013 and September 2014 with epistaxis under the otolaryngology team, 302 fulfilled the inclusion criteria and data collected from this group was used to derive a predictive model. All variables included were considered through univariate logistic regression analysis to ascertain statistically significant variables, with estimation of prevalence and odds ratios with corresponding 95\% confidence intervals (Table1 shows the regression analysis).

\section{RHINO-ooze score}

In order to elicit the co-variables which were statically significant in yielding our outcome (30-day re-admission), multivariate analysis with backwards elimination was employed. This yielded five factors that were most significantly associated with recurrent epistaxis requiring readmission: recent admission with epistaxis within the last 30 days, haemorrhage point unidentified, increasing age (age 70 years and above), posterior nasal packing at initial admission and oral anticoagulation usage (see literature review). The lowest beta-coefficient (obtained from the logistic regression study) value of the cofactors was then used to divide the other coefficient in order to attain the predictive scoring tool (Tables 2 and 3). The minimum and maximum scores were 0 and 8 respectively. The scores were stratified into low risk (0-3), medium risk (4-5) and high risk ( $\geq 6$ ) with good predictability (Table 3).

The predictive model was an overall a good fit as indicated in Table $4 \mathrm{a}, 4 \mathrm{~b}$ and $4 \mathrm{c}$ below and the multivariate logistic model had an ROC of 0.847 ( $95 \%$ confidence interval 0.801 to 0.885 ). Sample size for the logistic regression analysis suggested minimum sample size of 192 for the number of variables considered. In addition to estimating AUC for summarizing the model's discrimination, we used the Hosmer and Lemeshow test to test for goodness of fit and calibration.

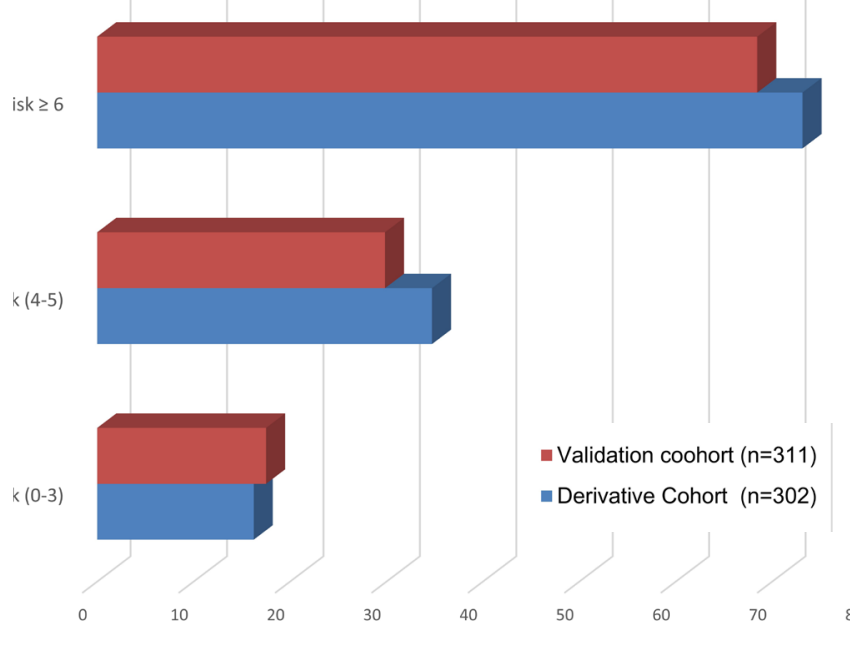

Figure 1. Bar chart showingthe relative percentage risk of 30-day readmission by risk category in the derivation and validation cohorts.

\section{Validation cohort}

Using the RHINO-ooze score, the prevalence of 30-day readmission risk categories in derivation and validation data sets were as follows; $16.2 \%$ and $17.5 \%$ were in the low risk category in the derivation and validation groups respectively, $34.7 \%$ and $29.9 \%$ as moderate risk and $73,1 \%$ and $68.5 \%$ as high risk patients (Figure 1). Overall the area under curve analysis of the validation group showed good concordance in terms of predictability and a RHINO-ooze score with AUC of 0.816.

Analysis of the high risk group (RHINO-ooze score $\geq 6$ ) showedsensitivity and specificity of $81 \%$ and $84 \%$, respectively.

\section{Discussion}

Epistaxis can have significant impact on patients with high morbidity and very rarely mortality. Patients with epistaxis are often elderly frail and usually suffer with other co-morbidities. Various conservative treatment modalities which can have significant discomfort are usually employed in managing patients, although these treatment modalities are safe generally, the sequelae can rarely result in mortality. Most patients often want to avoid these management options hence the opportunity to risk stratify those at high risk of readmission and offer other definitive management options. A decrease in readmission rates is highly beneficial for certain patient groups (high RHINO-ooze score).

It is clear that the rate of readmission/recurrence of epistaxis is unacceptable in most hospitals, there are high penalties associated with early readmission within the national healthcare service and it is estimated that the total penalties associated with readmissions would potentially cost NHS trusts $£ 584$ mil-

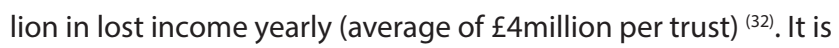
important to acknowledge that reducing our epistaxis readmission rate will not only decrease patient's morbidity but also 
Table 3. RHINO-ooze scoring tool; variables and scores.

\begin{tabular}{|lcc|}
\hline Criterion & Coefficients & Points \\
\hline Recent admission $<$ 30days & 0.988 & 1 \\
\hline $\begin{array}{l}\text { Haemorrhage point unidenti- } \\
\text { fied }\end{array}$ & 1.359 & 2 \\
\hline Increasing age $>70$ & 0.872 & 1 \\
\hline Nasal posterior pack required & 1.778 & 2 \\
\hline Oral anticoagulation & 1.362 & 2 \\
\hline Score range & Total & $\mathbf{8}$ \\
\hline $0-3$ & Probability of & Risk \\
\hline $4-5$ & $16.2 \%$ & interpretation \\
\hline$\geq 6$ & $34.7 \%$ & Low \\
\hline
\end{tabular}

avoid financial penalties.

Recent admission with epistaxis was found to be an independent factor in determining the risk of readmission. This is perhaps not surprising when we consider the rate of readmission following initial presentation. It should however be noted that in considering this factor, patients were not stratified into various groups (for example anterior versus posterior epistaxis or anticoagulant use). It was however clear from our study that admission with epistaxis increases the risk of further episodes of epistaxis by three to fourfold. There is increasing focus on the management of epistaxis to ensure better outcomes for patients and readmission reduction, this being the focus of the ongoing national epistaxis audit.

There is level $2 \mathrm{~b}$ evidence implicating unidentified bleeding point as one of the major reasons for readmission. There is evidence supporting the use on nasoendoscope in identifying the bleeding point ${ }^{(16,17)}$. This is, however, not routine in most National Health Service(NHS) hospitals; this may be due to lack of training for junior front-line staff involved in initial management of these patients. Most patients with epistaxis are initally managed by senior house officers who have little otorhinolaryngology experience in using rigid nasoendoscopes in assessing the nose. This reason combined with the lack of immediate availability of these endoscopes often implies that patients are not managed in this manner. Some authors have also reported high failure rates in patients with active bleeding at the time of endoscopic management ${ }^{(33)}$. In appropriately trained hands, most patients with epistaxis can be effectively and adequately managed using a rigid nasoendoscope to assess bleeding point and appropriately treat epistaxis at initial presentation with little complication. We accept that more research may be required to ascertain if this leads to better outcome for patients. Flexible
Table 4. A: Cox \& Snell analysis of the overall model fit; B: Hosmer \& Lemeshow test; $C$ : the area under the curve analysis.

\begin{tabular}{|lc|}
\hline Analysis & value \\
\hline A & \\
\hline Null model -2 Log Likelihood & 349.185 \\
\hline Full model -2 Log Likelihood & 249.393 \\
\hline Chi-squared & 99.792 \\
\hline DF & 5 \\
\hline Significance level & $P<0.0001$ \\
\hline Cox \& Snell R2 & 0.2814 \\
\hline Nagelkerke R2 & 0.4106 \\
\hline B & \\
\hline Chi-squared & 14.6382 \\
\hline DF & 7 \\
\hline Significance level & P \\
\hline C & 0.0409 \\
\hline Area under the ROC curve (AUC) & 0.0250 \\
\hline Standard error & 0.847 \\
\hline $95 \%$ Confidence interval & \\
\hline
\end{tabular}

endoscopes can also be used but these are usually more difficult to manipulate and perform cautery at the same time.

The use of posterior packs was found to be an independent variable in determining the risk of 30-day readmission. We controlled for confounders by including as many independent covariates in our regression analysis. In order to ensure that there was a distinction between patients with posterior packs and those that the bleeding point was unidentified, only patients in whom the bleeding point was identified as posterior before nasal packing was inserted where grouped into the posterior pack group. In this group of patients, bleeding was found to be too brisk for cauterisation hence posterior packing was then used. Majority of these patients went on to have nasal cautery upon removal of nasal pack with chemical cautery. It is not entirely clear why this particular group of patients treated in this way continue to have increased risk of readmission; this could be due to poor or inadequate cautery of the bleeding point.

Patients in whom the bleeding point was unidentified had significantly higher re-bleed rate and 30 day readmission rates. These patients were generally managed with nasal packing and received no further treatment upon removal of nasal pack as no bleeding point was identified. It is very likely that these patients re-bleed from the initial bleeding point and not due to trauma from the nasal pack as this will be evident after removal of pack. The vastly increased risk of re-admission in these patients sug- 
gests that further assessment with nasoendoscope and cautery may be appropriate. It also adds weight to our conclusion that patients who are high risk on the RHINO-ooze score should receive some form of definitive treatment to improve outcomes. The management of anticoagulated patients can be challenging, it is widely accepted that, in patients who are over anticoagulated reversal of coagulation usually resolves the epistaxis. In those who are within their range of international normalisation ratio, a period without coagulation may be of benefit. Patients on other forms of anticoagulants (aspirin, rivaroxaban) can also be managed with a period of nasal packing and cautery. It is however important to recognise the subset of patients who continue to have recurrent episodes of epistaxis and a discussion with haematologist/ general practitioners/cardiologist can sometimes lead to a multidisciplinary approach which can help prevent readmissions. Some patients on anticoagulants with recurrent epistaxis can rarely be managed with surgical intervention especially where a period of reversal of anticoagulation does not resolve the problem.

The RHINO-ooze score with its good sensitivity and specificity in predicting 30 day readmission can be used as an adjunct to clinical decision making and can help in risk stratifying patients who are likely to benefit from intervention. We believe that in patients who have had more than one admission the use of the RHINO-ooze score to predict further admission can provide a significant basis for definitive surgical management/intervention, especially in those patients who have not been successfully managed with immediate conservative management and continue to have recurrent episodes of epistaxis. Although Surgical management does not provide an absolute guarantee of recurrence, the rates of re-admission in patients groups following surgical intervention are significantly lower than those treated with conservative management.

It is however important to note that although our power calculations showed our sample size to be adequately powered for the study, we understand that a larger study may be beneficial in the future. With the advent of the national collaboration on outcomes for epistaxis undertaken by the British Rhinology Society (BRS), this may be the opportunity to ascertain the efficacy of this model on a national level.

\section{Conclusion}

We believe the RHINO-ooze score is an important tool and can be used to aide clinical decision making, it has the potential of not only reducing epistaxis readmission and morbidity but also avoiding the financial penalties accumulated by NHS trusts from excessive readmission of patients with epistaxis.

\section{Authorship contribution}

AA, PC: Data collection, analysis and write up; RK: Data collection and anlaysis; AL: Write up; PMD: Final review; $\mathrm{RH}$ : Write and final review.

\section{Conflict of interest}

No conflict of interest.

\section{References}

1. Gifford TO, Orlandi RR. Epistaxis. Otolaryngol Clin North Am. 2008;41:525-536 (viii)

2. Shukla PA, Chan N, Duffis EJ, Eloy JA, Prestigiacomo CJ, Gandhi CD. Current treatment strategies for epistaxis: a multidisciplinary approach. J Neurointerv Surg. 2013 Mar;5(2):151-6.

3. Schlosser RJ. Clinical practice. Epistaxis. N Engl J Med. 2009 Feb 19. 360(8):784-9.

4. Durr DG. Endoscopic electrosurgical management of posterior epistaxis: shifting paradigm. J Otolaryngol. 2004 Aug. 33(4):211-6.

5. Faistauer M, Faistauer A, Grossi, RS Roithmann R. Clinical outcome of patients with epistaxis treated with nasal packing after hospital discharge. Braz Otorhinolaryngol. 2009;75:857-865.

6. Soyka MB, Nikolaou G, Rufibach K, Holzmann D. On the effectiveness of treatment options in epistaxis: an analysis of 678 interventions. Rhinology. 2011;49:474-478.

7. Bray D, Giddings CEB, Monnery P, Eze N, Lo S, Toma AG. Epistaxis: are temperature and seasonal variations true factors in incidence? J Laryngol Otol. 2005 Sep;119(9):724-6
8. Koh, Elsie, Vincent I. Frazzini, and Nolan J. Kagetsu. "Epistaxis: vascular anatomy, origins, and endovascular treatment." American Journal of Roentgenology 174.3 (2000): 845-851.

9. Ando $Y$, limura J, Arai S, et al. Risk factors for recurrent epistaxis: importance of initial treatment. Auris Nasus Larynx. 2014 Feb;41(1):41-5.

10. Tomkinson A, Roblin DG, Flanagan P, Quine SM, Backhouse S. Patterns of hospital attendance with epistaxis. Rhinology. 1997 Sep;35(3):129-31.

11. McGarry GW. Nasal endoscope in posterior epistaxis: a preliminary evaluation. J Laryngol Otol. 1991 Jun;105(6):428-31.

12. Stankiewicz JA. Nasal endoscopy and control of epistaxis. Curr Opin Otolaryngol Head Neck Surg. 2004 Feb;12(1):43-5.

13. O'Leary-Stickney K, Makielski K, Weymuller EA Jr. Rigid endoscopy for the control of epistaxis. Arch Otolaryngol Head Neck Surg. 1992 Sep;118(9):966-7.

14. Elwany S, Abdel-Fatah H. Endoscopic control of posterior epistaxis. J Laryngol Otol. 1996 May;110(5):432-4.

15. Petruson B, Rudin R. The frequency of epistaxis in a male population sample. Rhinology 1975; 13:129.

16. Villwock JA, Jones K. Recent trends in epistaxis management in the United States: 2008-2010. JAMA Otolaryngol Head Neck Surg 2013; 139:1279.

17. Kotecha B, Fowler S, Harkness P, et al. Management of epistaxis: a national survey. Ann R Coll Surg Engl 1996; 78:444.

18. Pallin DJ, Chng YM, MCKay MP, et al. Epidemiology of epistaxis in US emergency departments, 1992 to 2001. Ann Emerg Med 2005; 46:77.

19. Tomkinson A, Roblin DG, Flanagan P, et al. Patterns of hospital attendance with epistaxis. Rhinology 1997; 35:129.

20. Zou Y, Deng YQ, Xiao CW, et al. Comparison of outcomes between endoscopic surgery and conventional nasal packing for epistaxis in the posterior fornix of the inferior nasal meatus. Pak J Med Sci. 2015 NovDec;31(6):1361-5.

21. Daniell HW. Estrogen prevention of recurrent epistaxis. Arch Otolaryngol Head Neck Surg 1995; 121:354.

22. Fishpool SJ, Tomkinson A. Patterns of hospital admission with epistaxis for 26,725 
patients over an 18-year period in Wales, UK. Ann R Coll Surg Engl 2012; 94:559.

23. Chiu TW, McGarry GW. Prospective clinical study of bleeding sites in idiopathic adult posterior epistaxis. Otolaryngol Head Neck Surg. 2007; 137: 390-393.

24. Lakhani R, Syed I, Qureishi A, Bleach N. The Wexham Criteria: defining severe epistaxis to select patients requiring sphenopalatine artery ligation. Eur Arch Otorhinolaryngol. 2013 Jul;270(7):2039-43.

25. Pope LER, Hobbs CGL. Epistaxis: an update on current management. Postgrad Med J.2005; 81: 309-314.

26. Denholm SW, Maynard CA, Watson HG. Warfarin and epistaxis - a case controlled study. J Laryngol Otol. 1993; 107: 195-196.

27. Srinivasan V, Patel H, John DG, Worsley A. Warfarin and epistaxis: should warfarin always be discontinued?. Clin Otolaryngol Allied Sci. 1997; 2: 542-544.

28. Jackson KR, Jackson RT. Factors associated with active, refractory epistaxis. Arch Otolaryngol Head Neck Surg. 1988; 114: 862-865.

29. Stadler RR, Kindler R, Holzmann D, Soyka MB. The long-term fate of epistaxis patients with exposure to antithrombotic medication. Eur Arch Otorhinolaryngol. 2016 Sep;273(9):2561-7.

30. Zhi T, Liu Y, Liu F. Clinical study of treatment of epistaxis of little's area by microwave, anterior nasal packing and trichloroacetic acid cautery. J Clin Otolaryngol. 1999 Nov;13(11):501-2.

31. Badran K, Malik TH, Belloso A, Timms MS. Randomized controlled trial comparing Merocel and RapidRhino packing in the management of anterior epistaxis. Clin Otolaryngol. 2005 Aug;30(4):333-7.

32. Friedman B, Basu J. The rate and cost of hospital readmissions for preventable conditions. Med Care Res Rev. 2004 Jun;61 (2):225-40.

33. Schwartzbauer HR, Shete M, Tami TA. Endoscopic anatomy of the sphenopalatine and posterior nasal arteries: implications for the endoscopic management of epistaxis. Am J Rhinol. 2003;17(1):63-66.

\section{Alfred Addison}

Otorhinolaryngology

John Radcliffe Hospital

Oxford

Headley Way

United Kingdom

E-mail: addison.alfred@gmail.com

\section{ADVERTISEMENT}

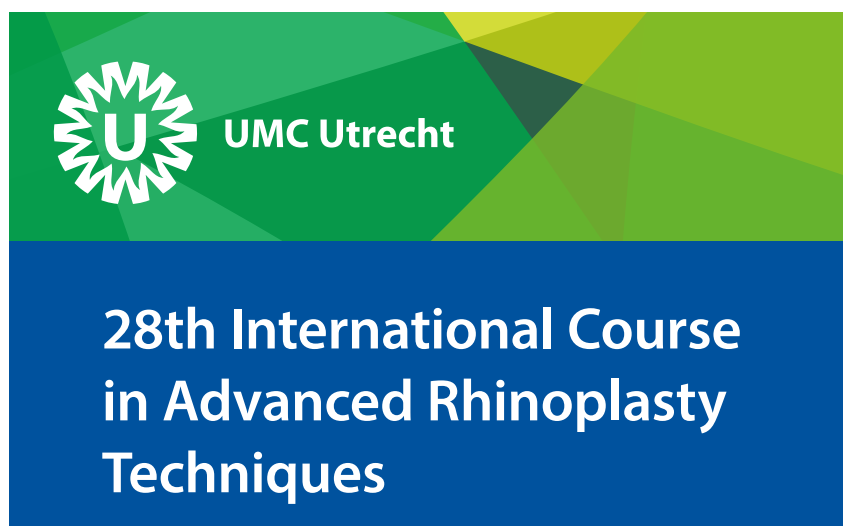

18 - 20 October, 2017

\section{UMC Utrecht, The Netherlands}

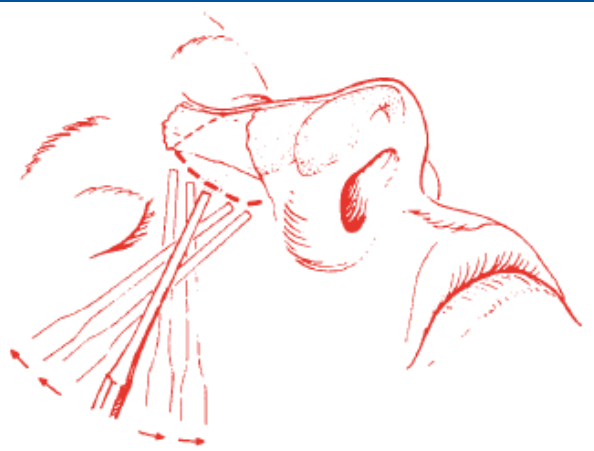

Course Directors: D.J. Menger \& G.J. Nolst Trenité

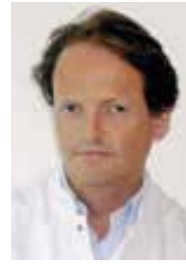

Dirk Jan Menger

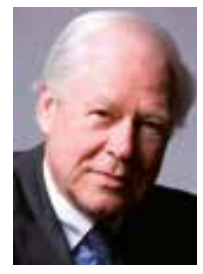

Gilbert Nolst Trenité

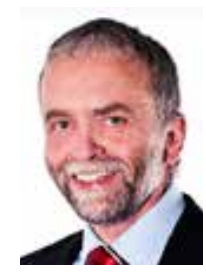

W. Gubisch
Teacher of honour: Wolfgang Gubisch, Stuttgart, Germany

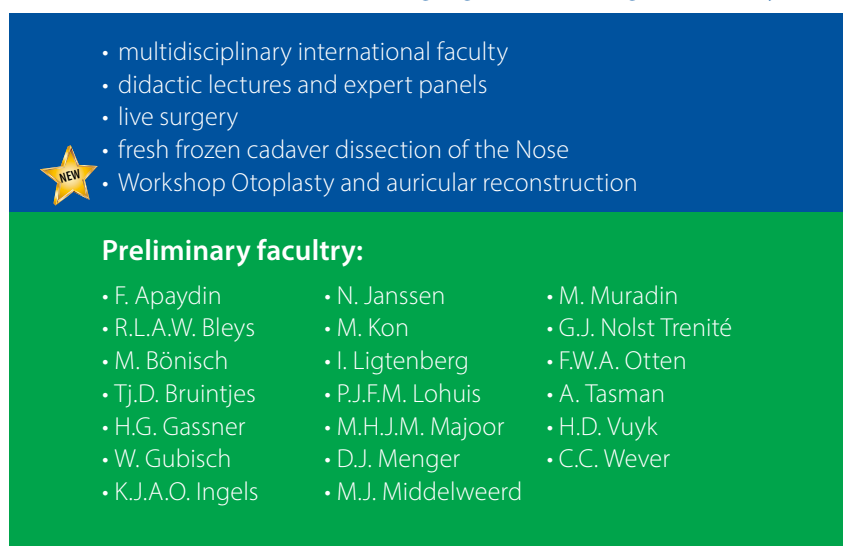

Information: rhinoplasty@umcutrecht.nl website: www.advancedrhinoplasty.nl

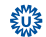

